\title{
Nurse coaching improves healthy conditions: an integrative review of the literature
}

\author{
Elsa Vitale,${ }^{1}$ Francesco Germini ${ }^{2}$ \\ ${ }^{1}$ Department of Mental Health; and ${ }^{2}$ Direction of Nursing Profession, Local Healthcare Company Bari, Italy
}

\begin{abstract}
Coaching has become a popular strategy in a complex environment. Nurses who incorporate coaching into their professional practice broaden their skills and opportunities in the entire spectrum of health, wellness, and healing. The aim was to illustrate and compare coaching models and to address their relevance in health promotion. A literature review from 2010 to 2019 , retrieved from MEDLINE, reference tracking, and consultation of academic networks, has led to peer-reviewed articles on coaching models for health promotion. A total of 70 articles were found, 45 of which were excluded because too generic and not specific to the clinical nursing field. Finally, only 15 articles that well respected the inclusion criteria have been selected. The implementation of coaching can be seen in several health care fields, especially in nursing, to enhance health by empowering individuals.
\end{abstract}

\section{Introduction}

Health and wellness coaching is a multidimensional constant among health care professionals. ${ }^{1}$ Nurse trainers emphasize engaged and agreeing strategies with patients and support performance and practice challenges to ameliorate health and well-being, ${ }^{2}$ helping patients in health care system innovations. ${ }^{3}$ Specifically, they improve a positive organization, focused on the culture of health encouragement and illness safeguard network, in contrast to illness-centered and responding context. The Patient Protection and Affordable Care Act, the Healthy People 2020 advantage, and the National Prevention and Health Promotion Strategy for enhancing well-being are the major principles for nurse coaches and accessible in scien-

Correspondence: Elsa Vitale, Department of Mental Health, Local Healthcare Company Bari, via X marzo 43, 70026 Modugno, Bari, Italy. E-mail: vitaleelsa@libero.it

Key words: Coaching; healthcare; health promotion; nursing; nurse coaching.

Conflict of interests: the authors declare no potential conflict of interests.

Received for publication: 17 April 2020.

Revision received: 15 January 2021.

Accepted for publication: 9 February 2021.

This work is licensed under a Creative Commons Attribution NonCommercial 4.0 License (CC BY-NC 4.0).

${ }^{\circ}$ Copyright: the Author(s), 2021

Licensee PAGEPress, Italy

Italian Journal of Medicine 2021; 15:135-144

doi:10.4081/itjm.2021.1297 tific literature. ${ }^{4}$ Also, nurse trainers belong to multiprofessional networks and are certified by the the $\mathrm{Na}-$ tional Consortium for Credentialing Health and Wellness Coaches (NCCHWC) and guide the manner in studying the health and wellness coaches in the future develops. ${ }^{5}$ An expert nurse coach is a registered nurse who improves abilities by finding guided and organized networks focused on relations with patients in order to improve and encourage patient aims, paying attention to the overall aspects of health, such as the biological, the psychosocial, the spiritual, the cultural, and the environmental dimension ${ }^{6}$ and by encouraging arrangements or guiding patients to specific skills. However, many studies demonstrate that health professionals are properly interesting with their patients when judgments are made and pay attention when transmitting information..$^{7-9}$

Nurses must strongly cooperate with physicians and other health care providers to advance a multitask pattern of health, flexibility, and well-being.

The nursing profession pays attention to ensuring the care of the whole person. For example, the American Holistic Nurses Association (AHNA) illustrated the Scope and Standards of Practice issues published in collaboration with the American Nurses Association (ANA), which show holistic nurses as 'opportunities of curative as references, partners, trainers and leaders' ${ }^{10}$

A core concept of holistic nursing tradition is helping self-finding and establishing their own engagement, focusing on a healing and team-working caring context to explore the self dimensions.

Newman described a person as a total combination who is uniformly seeking to maintain stability and arrangement between his or her internal and external circumstances. To encourage individuals to accomplish their aim, Newman formulated a nursing assessment 
method that focuses on patient-recognized demands. ${ }^{11}$ Dorothea Orem in her Self Care Model of Nursing Practice, introduces the association between nurse and patient as a connecting system that aimed to ameliorate health, well-being, and self-care starting from own patients' skills. Patricia Benner, also illustrated the relation patient/nurse as a mutual decision-making strategy reducing an individual's perspicacity. ${ }^{12}$

Sarah Hughes describes a complementary system as an important combination of training and counseling skills incorporated in the nurse coach model for illness management, which provides support to patients by exploring how they desire to control their health, including disease management and treatments. In addition, these techniques stimulate honesty, expectancy, and arisen knowledge of cooperative circumstances..$^{13}$

Susan Schenk declares that the nurse coach function can be described as increased interactional employment centered on mutual consideration for awareness and skills that both nurse and patient disclose to the condition. In this pattern, patients recognize their health purposes. The nurse coach enhances each person in an answering problem method, which increases one's selfefficiency. The idea of self-effectiveness, phases of transformation, and stimulated enhancement are mixed into nurse coaching or cooperation function. ${ }^{14}$

Through this idea, Albert Bandura illustrated selfefficacy as a key concept dimension to the nurse coaching practice, which guides nurses to monitor several dimensions of individual well-being and role and supplies a coherent system to support behavioral and lifestyle modifications in patients.

Lewis and Zahlis also adopt Bandura's self-efficacy model to explore clinical efforts of the coach in nursing to patients' happenings. They design nurse coaching as a professional advocating system that includes the managed patient, the nurse as an active listener who employs more and more exact insults to stimulate the person to the method of identifying problems and helps them in discovering responses to those requests. $\mathrm{Pa}$ tients are usually better adopt to identify their needs than the health care workers who care for them. ${ }^{15}$

The International Council of Nurses has currently cooperated with the Sigma Theta Tau International in releasing Coaching in Nursing. The report highlights nursing leadership's purpose in planning coaching recommendations and organizing an association between health and wellness coaching and nursing. In addition, the American Holistic Nurses Association arranged a national nursing task force that organizes the key points and promotes coach nursing by ameliorating basic curricula and conventional practice, encouraging the nursing coach function, which includes crucial theories and core skills for the nurse coach. ${ }^{16}$

In agreement with the New York State Nurse Practice Act, coaching is woven into nursing and based on the selected awareness and abilities that are the fundaments of the nursing profession. Correct communication to coaching in New York state training law declares that the practice as a registered nurse is shown to identify and handle human replies to verify possible health problems by case exploring, health education, health government, and development to help or therapeutic care of life and well-being. Each situation has its own Nurse Practice Act that controls the nursing system lawfully and ethically and regulates the standards of practice. Coaching communication is in the criterion of practice in most circumstances. ${ }^{17}$

In this work, an overview of the different clinical nurse coaching dimensions has been explored to review the available studies concerning the coaching methodology in nursing care to promote health among patients. Specifically, the research questions that guided this review were: i) What are the effects of the coaching approach in the field of health promotion within the nursing team? ii) What effects does the coaching technique have on the nurse-patient relationship? iii) What effects does the coaching approach determine in the nursing environment?

\section{Materials and Methods}

\section{Study design}

To achieve the objective of this study, an integrative review of the literature was conducted through the method proposed by Whittemore and Knalf ${ }^{18}$ as it allowed to systematically and rigorously analyze the results of the studies with different designs, both qualitative and quantitative, considering a comprehensive understanding of the topic.

\section{Research strategy}

The bibliographic search was carried out by consulting the MEDLINE database (through PUBMED) from January 2010 to December 2019. Limits were set in the bibliographic research phase: 'English language' and 'Italian language.' Keywords used for the bibliographic research were entered both freely and using the MeSH database, individually and in combination with the Boolean operators AND and OR: 'Coaching'; 'Healthcare'; 'Nursing'; 'Nurse coaching'; 'Health Promotion' (Table 1).

\section{Inclusion and exclusion criteria}

The review included all studies relating to the coaching methodology in the nursing practice: i) which had as the main purpose to investigate how coaching could influence health promotion; ii) with a study sample that included only nurses as health professionals; iii) which better interpreted the coach's 
function and properties, barriers and opportunities to the coaching system; iv) which better highlighted advantages and disadvantages in clinical nursing settings by health support.

On the other hand, studies: i) which did not have as their main objective the analysis of coaching in nursing practice as an approach to ensuring health; ii) with a sample that did not only include nursing professionals; iii) which only mentioned history and philosophy coaching; iv) which included only the coaching training program; v) grey literature; vi) checklist validation studies; vii) editorials; viii) holistic elements of care which not included only coaching; ix) mentor approach as promoting health which not included a coaching model in all its aspects, were excluded.

\section{Record selection process}

Through the bibliographic research on the MEDLINE database, all the articles considered potentially relevant for the purposes of the review were identified. First, an initial screening of qualifications and abstracts was performed in order to identify the number of po- tentially eligible articles for this review. Then, by considering the inclusion and exclusion criteria of the articles, further screening of the articles was carried out.

\section{Data extraction}

For each included article, all data necessary to describe the main characteristics and results were extracted: title, author(s), year of publication and journal, study design, sample and setting, main results, and conclusions. Next, the in-depth analysis of the studies was carried out through an interactive process of continuous reading and analysis of the contents, which in the first phase concerned the extraction of numerical data (quantitative studies) and textual data (qualitative data). Then, the extracted data were aggregated using a thematic approach to identify the main themes in all the studies illustrated through a descriptive summary. Subsequently, based on the recommendations of the Royal College of Nursing, ${ }^{19}$ a conceptual map (Figure 1) was developed according to the model of J.D. Novak ${ }^{20}$ to identify the characteristic points of the coaching approach in the nursing practice in promoting health.

Table 1. Search items in Medline (PubMed).

\begin{tabular}{|c|c|c|c|}
\hline Search & Add to builder & Query & Items found \\
\hline$\# 4$ & Add & Search ((coaching) OR nursing) OR health promotion & 898763 \\
\hline \#3 & Add & $\begin{array}{l}\text { Search (('mentoring'[MeSH Terms] OR 'mentoring2[All Fields] OR 2 coaching' } \\
\text { [All Fields]) AND ('nursing'[Subheading] OR 'nursing'[All Fields] OR 'nursing'[ } \\
\text { MeSH Terms] OR 'nursing'[All Fields] OR 'breast feeding'[MeSH Terms] OR ('breast' } \\
\text { [All Fields] AND 'feeding'[All Fields]) OR 'breast feeding'[All Fields]) AND 'nurses' } \\
\text { [MeSH Terms] OR 'nurses'[All Fields] OR 'nurse'[All Fields]) AND ('mentoring' } \\
\text { [MeSH Terms] OR 'mentoring'[All Fields] OR 'coaching'[All Fields]) AND ('health promotion' } \\
\text { [MeSH Terms] OR ('health'[All Fields] AND 'promotion'[All Fields]) OR 'health promotion' } \\
\text { [All Fields])) AND ('1/1/2010'[PDAT]: '31/12/2019'[PDAT]) }\end{array}$ & 56 \\
\hline$\# 2$ & Add & $\begin{array}{l}\text { Search Coaching Nursing Nurse Coaching Health Promotion Filters: Publication date from } \\
1 / 1 / 2010 \text { to } 31 / 12 / 2019\end{array}$ & 56 \\
\hline$\# 1$ & Add & Search Coaching Nursing Nurse Coaching Health Promotion & 70 \\
\hline
\end{tabular}

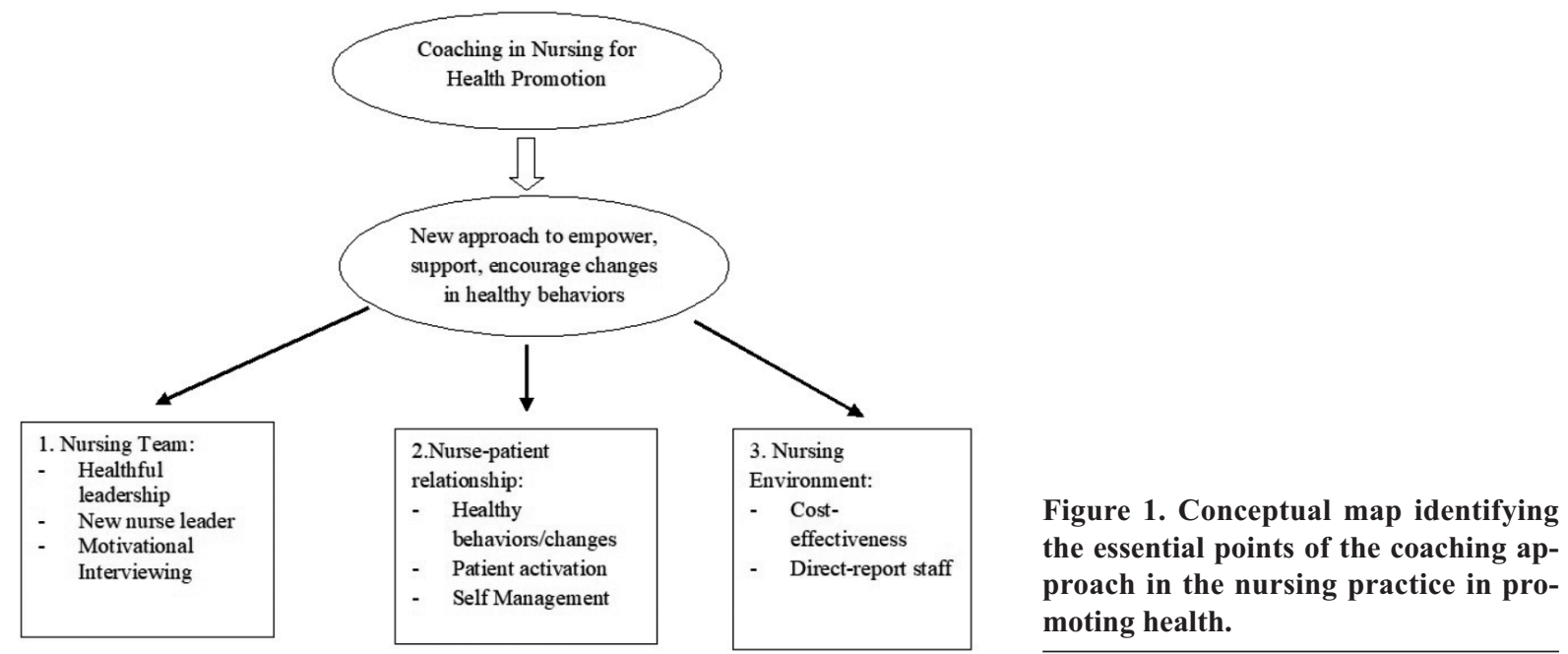




\section{Results}

\section{Articles selection}

Bibliographic research has made it possible to identify 70 relevant articles on the coaching methodology in nursing practice. Then, 12 titles and abstracts were screened, and of these, 22 full-text articles were considered eligible for review. A total of 15 articles were included in the final review. 7 articles were excluded as they did not answer the guiding questions of the review. Of these, 7 articles had a quantitative approach, 2 articles had a qualitative approach, 3 articles were literature reviews, and 3 were case studies. All the articles included in the revision are in English. The results of the article selection phase were summarized using the items in the PRISMA Statement ${ }^{21}$ (Figure 2).

\section{Characteristics of the studies}

The main characteristics of the included studies are summarized in Table 2. In total, the studies considered in this review were 15 . Of these, 7 were quantitive studies, ${ }^{22-28} 2$ qualitative studies, ${ }^{29,30} 3$ were literature reviews, ${ }^{31-33} 3$ are case studies. ${ }^{3-36}$

From the literature analysis, several salient aspects emerged relating to the strategy of coaching in nursing practice as a proactive strategy in promoting health. Specifically, the areas of competence of coaching in nursing practice highlighted in the literature were the following.

\section{The coaching approach in the nursing team}

Several coaching approaches in the nursing team experiences can improve health care services which are connecting with countries to discharge, perform and evaluate care development curricula. ${ }^{22}$ Also, health coaching methodology is considered a fresh approach for nurses, improving health outcomes and affecting nursing staff compliance. ${ }^{35} \mathrm{An}$ important role is considered the one of the nurse managers as a change coach in the nursing practice who can successfully move between the roles of change agent and change coach to continuously transform the environment and how the nursing care is delivered. Moreover, to promote healthy leadership development among direct-report staff and report outcomes, the literature proposes the motivational interviewing (MI) approach, which shows acceptability for MI use in the development of direct-report staff and other aspects of nursing leadership roles. It seems that the MI improves health care quality both among nurses and nurse-patients settings. ${ }^{31}$

\section{The coaching approach in the nurse-patient relationship}

The coaching approach in the wellness programs plays an important role since it significantly increases

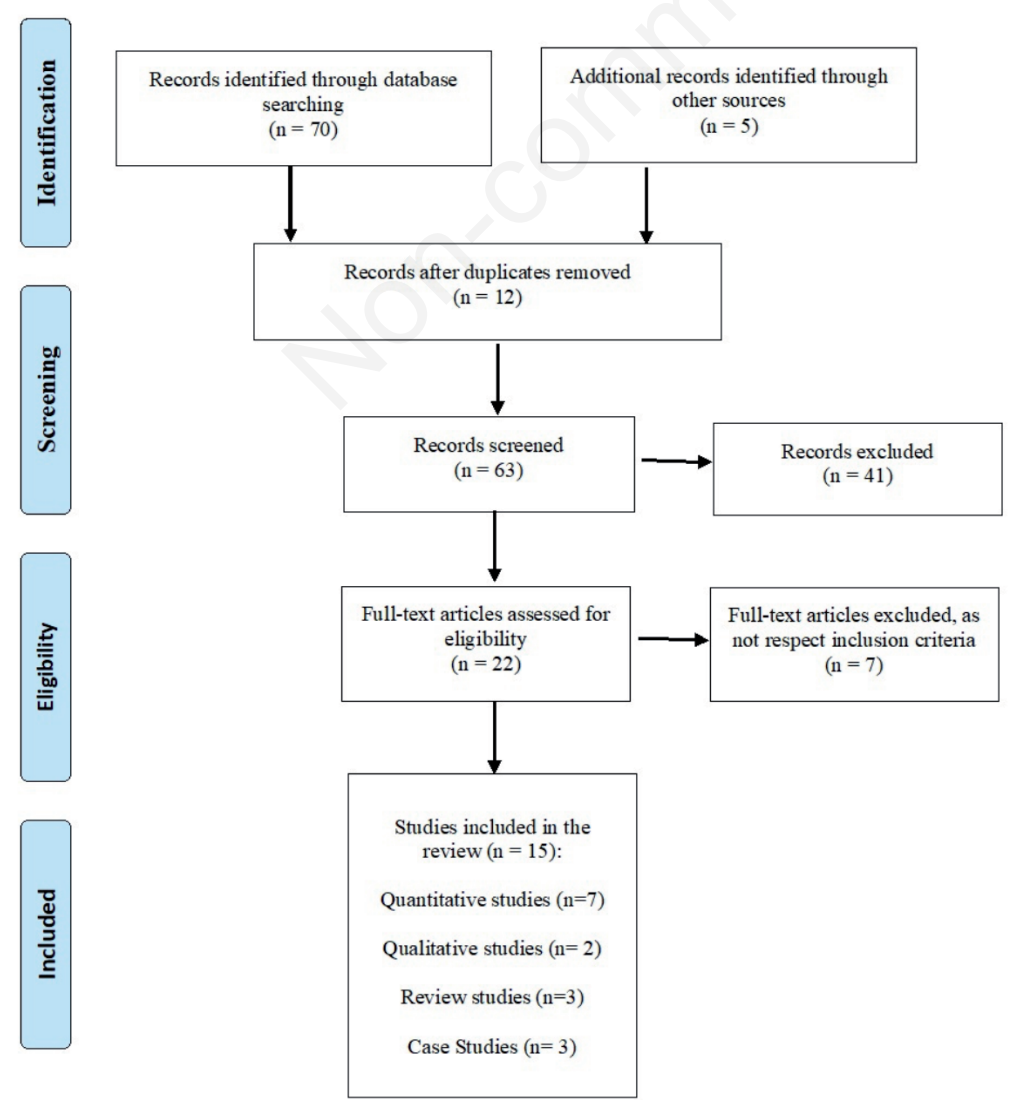

Figure 2. PRISMA 2009 flow diagram for the integrative review in: 'Nurse coaching improves health conditions'. 
the well-being of patients/population and improves their healthy lifestyles. ${ }^{22,28}$ Furthermore, the literature illustrated several coaching approaches for patients based on health promotion. For example, the Internet approach based on the health-promotion program to COPD patients (COPD is a progressive lung disease

Table 2. Characteristics of the studies included in the review.

\begin{tabular}{|c|c|c|}
\hline $\begin{array}{l}\text { Author(s) } \\
\text { year }\end{array}$ & $\operatorname{Aim}(s)$ & Design/Participants/Setting \\
\hline $\begin{array}{l}\text { 1. Altunkurek } \\
\text { S.Z., \& Bebis H. } \\
(2019)\end{array}$ & $\begin{array}{l}\text { To evaluate the impact of a } \\
\text { wellness coaching program } \\
\text { on the health behaviors of } \\
\text { eighth-grade students. }\end{array}$ & $\begin{array}{l}\text { A pretest/posttest randomized controlled } \\
\text { study was used. Students completed a } \\
\text { demographic information form, the Five- } \\
\text { Factor Wellness Scale-Adolescent Form } \\
\text { (5F-Wellness-AF), and the Adolescent } \\
\text { Lifestyle Scale (ALPS). The wellness } \\
\text { coaching program of group education, } \\
\text { individual consulting, physical activity, and } \\
\text { health education was provided for } 12 \text { weeks. } \\
\text { The study population comprised } 132 \\
\text { adolescents (Wellness Coaching Group } \\
n=33 \text {, Health Education Group } n=33 \text {, } \\
\text { Control Group } n=66 \text { ). }\end{array}$ \\
\hline
\end{tabular}

Findings/Implications in nursing practice

The result of a 3-day coaching education

2. Ammentorp, J., $\quad$ suggested to neonatal $\&$ Kofoed, P.E. (2010) intervention study nurses is explored in an assessing the nurses' selfefficacy before and after the training.

To explore the feasibility of an off-the-shelf Internet-based health-

3. Early F., Young J.S., Robinshaw E., Mi E.Z., Mi E.Z., Fuld J.P. (2017)

\section{promotion program, the} Preventive Plan (TPP) coupled with nurse-coach support for home-based self-management of COPD with a focus on patient activation.

Transitional care is an essential component of the Patient Protection and Affordable Care Act (PPACA) of 2010.

4. Hennessey B., Medicare \& Medicaid \& Suter, P. (2011) Services aimto connect with countries to discharge, perform, and evaluate care development curricula.
Quantitative pilot study.

A total of $39 / 44(89 \%)$ and $31 / 40(78 \%)$ neonatal nurses answered the questionnaire before and after the course, respectively.
This wellness coaching program significantly increased the wellness of adolescents and improved their healthy lifestyle behaviors. This program can be used together with health education provided by a public health nurse.
Case series design.

19 COPD patients were recruited, and 14 completed 3-month follow-up in two groups: groups 1 and 2 with more and less advanced COPD.

Benefits and user experience were explored in semi-structured interviews, analyzed thematically.
Coaching can ameliorate nurses' selfeffectiveness in association with the necessities of the mothers and fathers. Coaching could be a method that can maximize the personal and professional potential of the staff and prepare them for the mindful being-in-relation approach that is being requested increasingly.

The feasibility of combining nurse-coach support aligned to an Internet-based health resource, TPP, in COPD and provide learning about the challenges of such an approach and the importance of the nursecoach role.
Observational cohort study.

One version embraces a one-to-one coach nurse-patient association, where the former acquires the role of modeling self-care. Another advanced practice nursing pattern is transition coaching.
A health coach is not uniformly described, and needs minimal reworking.
How health coaching works, how it affects compliance, and why traditional approaches have fallen short.
A case study in health coaching as a fresh approach for improving health outcomes and reducing costs.
Health coaching guides others to discover and address their ambivalence about health behavior change.

The traditional health teaching method of 'do as I say' is replaced with concepts that include working from the individual's agenda, using active listening, and engaging in change talk.

Health coaching has been shown to improve health outcomes and reduce costs. This aligns with the occupational health nurse's role of promoting and restoring health, reducing risk, and monitoring chronic conditions.

The nurse-coache intervention 'focused on giving information, interpreting the experience, and validating

6. Jones D., Duffy M.E., \& Flanagan, and clarifying responses and actions related to the surgical experience directed toward making a difference in recovery outcomes.'
The study sample is a randomized clinical trial with repeated evaluations. 102 subjects (52 in the intervention group and 50 in the control group) were recruited. Symptom distress was assessed with the Symptom Distress Scale, and functional health was measured using the Medical Outcomes Study.
Immediate postoperative telephone calls from nurses displayed an amelioration in patients' physical and mental health state in reducing distress symptoms.

To be continued on next page 
Table 2. Continued from previous page.

\begin{tabular}{l}
$\begin{array}{l}\text { Author(s) } \\
\text { year }\end{array} \quad$ Aim(s) $\quad$ Design/Participants/Setting \\
\hline
\end{tabular}

To examine district nurses' experiences of working

7. Lunderberg K. Jong M.C.,

Kristiansen L., \&

Jong M.

(2018) with health preventive actions among patients with risk factors for cardiovascular disease (CVD) and identify facilitators and obstacles in Health Promotion Practice (HPP).
A qualitative approach where individual semi-structured interviews were performed with a total of 12 district nurses in primary care. Data transcripts were analyzed with manifest content analysis.

\section{Findings/Implications in nursing practice}

Five categories were identified. Firstly, informants regarded HPP as the core essence of their work. Secondly, counseling and coaching were reported as crucial elements in working with HPP. Thirdly, informants identified tools such as motivational interviewing (MI) to facilitate HPP. In the fourth category facilitators and barriers of HPP appeared, consisting of both positive and negative attitudes and presence as well as lack of organizational culture and structure. Finally, some informants were dissatisfied with HPP and viewed it as compulsory or as a burden, while others were satisfied and experienced it as a stimulating challenge.

HPP is the core of the district nurses' work to promote a healthier lifestyle in individuals with CVD.

Occupational health nurses own the competencies and methods to efficiently and safely report optimal health goals thanks to the knowledge of chronic conditions, evidence-based practice, and health coaching.
8. Miller C. (2011) health coaching with regard to occupational health nursing practice.
A simulation of a case study in 'Health Coaching Session' was performed.

To identify evidence supporting the application of Motivational Interviewing (MI) strategies and principles by

9. Niesen C.R., Kraft S.J., Meiers S.J. (2018) nurse leaders to promote healthy leadership development among direct-report staff and report outcomes of an educational pilot project regarding MI use for new nurse leaders.
Literature review on MI - Project research to correlate MI strategies and the American Organization of Nurses Executives competencies.
Survey responses were gathered from new nurse supervisors and nurse managers following the MI educational session for nurse leaders. The results show acceptability for MI use in the professional development of direct-report staff and other aspects of nursing leadership roles.
10. Oksman E., Linna M.,

Horhammer L., Lammintakanen J., \& Taljia M. (2017)

11. Potempa K.M.,
Butterworth S.W.,
Flaherty-Robb
M.K., \& Gaynor
W.L.
$(2010)$

12. Rivers R. Pesata V., Beasley M., \& Dietrich, M. (2011)
To evaluate a cost effectiveness analysis of a tele-based health-coaching intervention among patients with type 2 diabetes (T2D), (CAD) and congestive heart failure (CHF). coronary artery disease

\section{The model draws on} empirical and applied coaching techniques in different contexts in health promotion, as obesity and chronic diseases management. Explanation of the role of nursing coaching in accordance with the United Nations Review of the literature

Descriptive study.
Randomized Control Trial study. A total of 1570 patients were blindly randomized to intervention $(\mathrm{n}=970)$ and control $(n=470)$ groups. The intervention group received monthly individual health coaching by telephone from a specially trained nurse for 12 months and routine social and health care. Patients in the control group received routine social and health care. Quality of life was assessed at the beginning of the intervention, and follow-up measurements were made after 12 months of health coaching. The cost included all direct healthcare costs supplemented with home care and nursing

home-care costs in social care. The utility was based on a Health-Related Quality of Life(HRQoL)measurement, and costeffectiveness was assessed using incremental cost-effectiveness ratios (ICERs)

Millennium Development Goals (MDGs).
The cost-effectiveness of health coaching was highest in the T2D group. The ICER for the CAD group was more modest, and in the CHF group, costs increased with no marked effect on QoL.

The cost-effectiveness of health coaching may vary substantially across patient groups, and thus interventions should be targeted at selected subgroups of chronically ill. Health coaching improved the QoL of T2D and CAD patients with moderate costs.
Suggestions described clinical application and further developing model in nurse coaching skills.

The Healthy Ageing Model is anchored in an established theory on motivation and health behavior change. Professional nurse coaches can improve new strategies to ameliorate national and global health by empowering individuals and groups to support and encourage changes that lead to a healthy lifestyle and healthy communities. 
Table 2. Continued from previous page.

\begin{tabular}{|c|c|c|c|}
\hline $\begin{array}{l}\text { Author(s) } \\
\text { year }\end{array}$ & $\operatorname{Aim}(\mathbf{s})$ & Design/Participants/Setting & Findings/Implications in nursing practice \\
\hline $\begin{array}{l}\text { 13. Robins J.L.W., } \\
\text { Kiken L., Holt M., } \\
\text { McCain N.L. } \\
(2014)\end{array}$ & $\begin{array}{l}\text { Overview of the } \\
\text { mechanisms of action, } \\
\text { evidence base, and practice } \\
\text { of mindfulness, } \\
\text { emphasizing how to easily } \\
\text { incorporate this valuable } \\
\text { skill into practice. }\end{array}$ & $\begin{array}{l}\text { Review of the literature in PubMed, } \\
\text { CINAHL, PsychInfo Databases. }\end{array}$ & $\begin{array}{l}\text { Conscious attention to the present moment in } \\
\text { a receptive way is known as } \\
\text { mindfulness. A growing body of research } \\
\text { indicates that mindfulness can be taught and } \\
\text { cultivated to improve physical and mental } \\
\text { health. } \\
\text { As part of the coaching competency, } \\
\text { mindfulness can be practiced and taught by } \\
\text { advanced practice nurses to support lifestyle } \\
\text { and behavioral changes, } \\
\text { decrease perceived stress, enhance the } \\
\text { quality of life, and, ultimately, improve } \\
\text { health and health outcomes. }\end{array}$ \\
\hline $\begin{array}{l}\text { 14. Stefancyk A., } \\
\text { Hancock B., \& } \\
\text { Meadows, M.T. } \\
\text { (2013) }\end{array}$ & $\begin{array}{l}\text { The new vision of nurse } \\
\text { coaching was described, in } \\
\text { which coaching builds } \\
\text { changes through nursing } \\
\text { management. }\end{array}$ & $\begin{array}{l}\text { Changes in the coaching behaviors were } \\
\text { highlighted, which included: guidance, } \\
\text { facilitation, and inspiration to inspire others } \\
\text { toward change, altering human capabilities, } \\
\text { supporting and influencing others toward } \\
\text { change. }\end{array}$ & $\begin{array}{l}\text { An exemplar of the nurse manager's role as a } \\
\text { change coach in practice is provided using } \\
\text { the American Organization of Nurse } \\
\text { Executives' Care Innovation and } \\
\text { Transformation initiative. } \\
\text { The agile manager can successfully move } \\
\text { between the roles of change agent and } \\
\text { change coach to continuously transform the } \\
\text { environment and how care is delivered. }\end{array}$ \\
\hline $\begin{array}{l}\text { 15. Tripp S.B., } \\
\text { Perry J.T., } \\
\text { Romney S., } \\
\text { Blood-Siegfried J. } \\
(2011)\end{array}$ & $\begin{array}{l}\text { The National Association } \\
\text { of Pediatric Nurse } \\
\text { Practitioners' Healthy } \\
\text { Eating and Activity } \\
\text { Together guidelines were } \\
\text { adopted in a rural pediatric } \\
\text { office. }\end{array}$ & $\begin{array}{l}\text { After a 6-month pilot, the effectiveness of } \\
\text { treatment was evaluated with a retrospective } \\
\text { chart review. }\end{array}$ & $\begin{array}{l}\text { Children were motivated to make healthy } \\
\text { lifestyle changes but had difficulty } \\
\text { maintaining motivation and compliance with } \\
\text { those choices after } 1-2 \text { months. However, } \\
\text { with the consistent use of motivational } \\
\text { interviewing techniques combined with diet } \\
\text { and exercise counseling, there was a trend } \\
\text { toward lower body mass index and waist } \\
\text { measurements. }\end{array}$ \\
\hline
\end{tabular}

causing breathlessness, cough, fatigue, reduced exercise capacity, and frequent infections, with high societal burden) which also includes nurse-coaching support for home-based where patients' self-manage their activities. The feasibility of combining nursecoach support with the Internet-based resource provides learning about the nurse-coach role's challenges in the COPD patients support. ${ }^{34}$

Moreover, another coach nursing approach described in the literature is the telephone call. For example, in the Jones et al. study, ${ }^{25}$ the nurse-coached intervention focused on giving information, interpreting the experience, validating and clarifying responses and actions related to surgical experiences. This randomized clinical trial shows that telephone calls after surgery displayed an amelioration in patients' physical and mental health, decreased physical and mental health, and decreased distress symptoms. Moreover, health promotion is considered the core essence of the nursing coach approach to patients, particularly counseling and coaching were reported as crucial elements in health promotion. In fact, professional nurse coaches can improve new strategies to ameliorate national and global health by empowering individuals and groups to support and encourage changes that lead to healthy lifestyles. ${ }^{28,32}$

Suggestions describe the clinical application and further developing models in nurse coaching skills. For example, in the Pontempa et al. study ${ }^{27}$ the nurse coaching model is linked to the Healthy Ageing Model establishing theory on motivation and health behavior change in health promotion as obesity and chronic diseases management. In addition, however, MI is often identified as an informant tool to patients aimed at promoting healthy behavior.

\section{The nursing environment and the cost-benefit ratio of coaching in nursing practice}

Health coaching can be an integrated part of occupational health nurses' strategies to affect employee health management behavior and health outcomes. Health coaching provides occupational health nurses with the framework from which to engage and assist employees in identifying ambivalence concerning positive lifestyle changes under their nurses' self-effectiveness in associationwith the necessities of clients. Coaching can be considered as a method to maximize the personal and professional potential of the nursing staff and prepare them for the mindful being. ${ }^{23}$

Moreover, Niensen et al. ${ }^{31}$ study demonstrated that the MI be considered a beneficial approach for promoting health behavior changes among patients and an innovative nursing leaders' approach toward coaching. The MI can be tested as a part of a formal leadership succession planning to support the professional development and performance of direct-report colleagues through efficient and effective coaching approaches. Health coaching improves the quality of life 
in chronically ill patients, decreasing perceived stress and influences. In addition, the cost-effectiveness of health across patient groups improves health and its outcomes..$^{26,33}$

\section{Discussion}

In all research, , finding an advancing emphasis on coaching has been paying, particularlyin health improvements. However, the recent core on well-being and health managerial will require the government of a profession available for answering to innovations and performing health and well-being of persons, families, and society. ${ }^{37}$

In all selected studies of this review, the coaching approach is described as an innovative method to perform patient health and help individuals to advance self-consciousness competencies for themselves.

Many studies considered illustrated also coaching training among nurses to improve nursing coach methodologies and emphasize an enthusiastic and a creative approach, associated with outcomes and focused on the relationship between patient and nurse, whose main purpose is the health and well-being promotion of the whole individual.

By considering these studies and their findings, it has been highlighted that professional nurse coaches can perform new strategies to improve global wellbeing by addressing patients and their social contexts to healthy lifestyles. Therefore, the coaching advancement can be underlined in several dimensions in the nursing practice; specifically, nurse coaches support health in all its dimensions: biological, psychological, social, spiritual, cultural, and environmental. ${ }^{38}$

Furthermore, this review can underline a few approaches to coaching that can help in the nursing practice, but it cannot indicate only one as the most effective.

All the research included in this review agrees with the Luck ${ }^{39}$ statement coaching skills, which embraces a state of coaching involving: a secure dimension, caring patient-focused relationship, deep listening, accurate communication competencies to develop self-consciousness, critical interventions, and self-capability to support the curative progress. Combining counseling and teaching abilities improves the nurse coaching standard linked with patients' contribution aim and support self-effectiveness. ${ }^{40}$ Nurses embrace instruments to progress health coaching courses that cover national recommenced focus on well-being and patient-involved care. The combination of mentoring and counseling competencies supports the nurse coaching approach to patients by establishing aims and encouraging self-efficacy. Coaching can be considered a logical development of where nurses wish to advance and both the expression in nursing practice guidelines. Coaching competencies strengthen professional practice in several approaches and in the future may grow an important ability as nurse self-care in a needy dimension of successful coaching. Coaching is an innovative strategy of being with individuals combined with counseling. Attention to health and wellness will improve nursing practice and may be the most significant contribution to forthcoming generations and nursing's most enduring legacy.

\section{Limits}

The results of this review must be considered taking into account some research limitations that mainly concern the execution of studies in the literature that respond to the concepts of reliability, credibility and transferability. Reliability means the achievement of consistent results, credibility means the degree to which it is believed that the results have been correctly analyzed, and transferability refers to the degree to which the results of a qualitative study can be generalized or transferred to other contexts or settings. ${ }^{41} \mathrm{Fi}$ nally, the heterogeneity of the study contexts understood as the variability of clinical governance with respect to the type of patients and the diseases studied (type of patient, the severity of his condition) and characteristics of the nursing organization (organization, leadership styles) can explain the differences between the various studies.

\section{Conclusions}

In conclusion, this integrative review highlights that coaching skills in the nursing practice improve nursing quality in health promotion. However, coaching approaches can be ameliorated through more nursing practice concerns and nurse coaching competencies among nurses and their leaders.

Since the scientific literature has demonstrated that coaching competencies improve the cost-effectiveness in health care delivery, coaching can be performed in its clinical practice as an important target to reach.

However, in order to better understand the coaching technique, further studies should be conducted, especially in the Italian context, where research in this area is totally absent. In order to investigate factors hindering the coaching technique, to propose organizational solutions that produce proactive improvement strategies in the field of assistance. ${ }^{42,43}$ Exploring the approach of coaching in the nursing and student fields could be important. The latter in order to identify any opportunities to encourage health promotion for patients, among nurses and students ${ }^{43}$ perhaps also with a view to multi-professionalism and multidisciplinary, already adopted in other different areas of nursing, such as in the orthopedic field. ${ }^{44,45}$ 


\section{References}

1. Lawson K. Could health coaching build a bridge to a new system of healthcare? Altern Ther Health Med 2009;15:16-8.

2. Dossey B. Professional nurse coaching: advances in national and global healthcare transformation. Global Adv Health Med 2013;2:10-6.

3. Bridges RA, Holden-Huchton P, Armstrong ML. Accelerated second degree baccalaureate student transition to nursing practice using clinical coaches. J Contin Educ Nurs 2013;44:225-9.

4. Pearlman SA. The patient protection and affordable care act: impact on mental health services demand and provider availability. J Am Psychiatr Nurses Assoc 2013;19:327-34.

5. Harrington SE. U.S. Health-care reform: the patient protection and affordable care act. J Risk Insurance 2010;77:703-8.

6. DeCampli P, Kirby KK, Baldwin C. Beyond the classroom to coaching: preparing new nurse managers. Crit Care Nurs Q 2010;33:132-7.

7. Wolever RQ, Eisenberg DM. What is health coaching anyway? Standards needed to enable rigorous research. Arch Intern Med 2011;171:2017-8.

8 . Hess D. Defining holistic nurse coaching. Beginnings 2011;31:18-9.

9. Schaub BG, Luck S, Dossey B. Integrative nurse coaching for health and wellness. Altern Complement Ther 2012;18:14-20.

10. Jasemi M, Valizadeh L, Zamanzadeh V, Keogh B. A concept analysis of holistic care by hybrid model. Indian J Palliat Care 2017;23:71-80.

11. Mudd A, Feo R, Conroy T, Kitson A. Where and how does fundamental care fit within seminal nursing theories: A narrative review and synthesis of key nursing concepts. J Clin Nurs 2020;29:3652-66.

12. Mills J, Wand T, Fraser JA. Exploring the meaning and practice of self-care among palliative care nurses and doctors: a qualitative study. BMC Palliat Care 2018;17:63.

13. Hughes S. Promoting independence: the nurse as coach. Nurs Stand 2003;18:42-4.

14. Schenk S, Hartley K. Nurse coach: healthcare resource for this millennium. Nurs Forum 2002;37:14-20.

15. Bandura A. Self-efficacy: toward a unifying theory of behavioral change. Psychol Rev 1977;84:191-215.

16. Donner GJ, Wheeler MM. Coaching in nursing: an introduction. Geneva, Switzerland: International Council of Nurses; IN: Sigma Theta Tau International; 2009.

17. Wolever RQ, Simmons LA, Sforzo GA, et al. A systematic review of the literature on health and wellness coaching: defining a key behavioral intervention in healthcare. Glob Adv Health Med 2013;2:38-57.

18. Whittemore R, Knalf $K$. The integrative review: updated methodology. JAN 2005;52:546-53.

19. Royal College of Nursing. Case management form. London: RCP; 2019.

20. Novak JD, Canas AJ. The origins of the concept maps and how to construct them. Pensacola, FL: Institute for Human and Machine Cognition; 2006.

21. Mother D, Liberati A, Tetzlaff J, Altman DG. The PRISMA Group. Preferred reporting items for system- atic reviews and meta-analyses: the PRISMA statement. PLoS Med 2009;6(7).

22. Altunkurek SZ, Bebis H. The effects of wellness coaching on the wellness and health behaviors of early adolescents. Public Health Nursing 2019;36:488-97.

23. Ammentorp J, Kofoed PE. Coach training can improve the self-efficacy of neonatal nurses. A pilot study. Patient Educ Couns 2010;79:258-61.

24. Hennessey B, Suter P. The community-based transitions model: one agency's experience. Home Healthc Nurse 2011;29:218-30.

25. Jones D, Duffy ME, Flanagan J. Randomized clinical trial testing efficacy of a nurse coached intervention in arthroscopy patients. Nurs Res 2011;60:92-9.

26. Oksman E, Linna M, Horhammer L, et al. Cost-effectiveness analysis for a tele-based health coaching program for chronic disease in primary care. BMC Health Serv Res 2017;17:138.

27. Potempa KM, Butterworth SW, Flaherty-Robb MK, Gaynor WL. The Healthy Ageing Model: health behaviour change for older adults. Collegian 2010;17:51-5.

28. Tripp SB, Perry JT, Romney S, Blood-Siegfried J. Providers as weight coaches: using practice guides and motivational interview to treat obesity in the pediatric office. J Pediatr Nurs 2011;26:474-9.

29. Lundberg K, Jong MC, Kristiansen L, Jong M. Health promotion in practice-district nurses' experiences of working with health promotion and lifestyles interventions among patients at risk of developing cardiovascular disease. Explore 2017;13:108-15.

30. Stefancyk A, Hancock B, Meadows MT. The nurse manager: change agent, change coach? Nurs Adm Q 2013;37:13-7.

31. Niensen CR, Kraft SJ, Mejers SJ. Use of motivational interviewing by nurse leaders. Coaching for performance, professional development, and career goal setting. Health Care Manager 2018;37:183-92.

32. Rivers R, Pesata V, Beasley M, Dietrich M. Transformational leadership: creating a prosperity-planning coaching model for $\mathrm{RN}$ retention. Nurse Leader 2011;9:48-51.

33. Robins JLW, Kiken L, Holt M, McCain LN. Mindfulness: an effective coaching tool for improving physical and mental health. J. Am. Assoc. Nurse Pract 2014;26:511-8.

34. Early F, Young JS, Robinshaw E, et al. A case series of an off-the-shelf online health resource with integrated nurse coaching to support self-management in COPD. Int J COPD 2017;12:2955-67.

35. Huffman MH. Health Coaching. A fresh approach for improving health outcomes and reducing costs. AAOHN J 2010;58:245-50.

36. Miller C. An integrated approach to worker self-management and health outcomes: Chronic conditions, evidence based practice, and health coaching. AAOHN J 2011;59:491-501.

37. Rachele JN, Washington TL, Cuddihy TF, et al. Valid and reliable assessment of wellness among adolescents: Do you know what you're measuring? Int J Wellbeing 2013;3:162-72.

38. Bircher J, Kuruvilla S. Defining health by addressing individual, social, and environmental determinants: new opportunities for health care and public health. J Public Health Pol 2014;35:363-86. 
39. Luck S. Changing the health of our nation - the role of nurse coaches. Altern Ther Health Med 2010;16:78-80.

40. Myers JE, Sweeney TJ. Wellness counseling: the evidence base for practice. J Counsel Develop 2008;86:482-93.

41. Pearson A, Jordan Z, Munn Z. Translational science and evidence-based healthcare: a clarification and reconceptualization of how knowledge is generated and used in healthcare. Nurs Res Pract 2012;2012:792519.

42. Old N. Paving the way for health promotion nurses: an international perspective. Creat Nurs 2014;20:222-6.

43. Vitale E. Clinical teaching models for nursing practice: a review of literature. Profess Inf 2014;67:117-25.

44. Vitale E, Notarnicola A, Tafuri S, et al. Orthopedic Multidimensional Prognostic Index (Ortho-MPI) in the elderly with hip or neck femur fracture: a pilot study. Arch Gerontol Geriatr 2014;58:101-4.

45. Vitale E, Notarnicola A, Moretti L, et al. Multidimensional prognostic index in the elderly with hip or neck femur fracture. Orthop Rev 2012;4:e15. 